\title{
Online-mobile service cross-channel cognitive evaluations in a multichannel context
}

\author{
J. Nel * and C. Boshoff \\ Department of Business Management, University of the Free State, PO Box 339, Bloemfontein, South Africa, 9300 \\ Department of Business Management, Stellenbosch University, Private bag X1, Matieland, Stellenbosch, South Africa, 7602 \\ *To whom all correspondence should be addressed \\ Nelj@ufs.ac.za
}

\begin{abstract}
Since the advent of mobile commerce, many firms have added a mobile (m-) service to their existing offline and online services. The adoption of an $\mathrm{m}$-service in a multichannel context is not only influenced by factors directly associated with the m-service, but also by cross-channel cognitive evaluations emanating from other existing channels. These cross-channel evaluations can lead to evaluative synergies and dissynergies that can influence consumer decision-making. To explore empirically the impact of cross-channel synergies and dissynergies between the online service and the m-service offered by the same firm, against the background of expectation-transfer theory and status-quo-bias theory, data were collected from 666 online-service users. Consistent with expectation-transfer theory and status-quo-bias theory, the results of the study demonstrated that cross-channel evaluative synergies and dissynergies do indeed impact salient m-service beliefs. The results suggest that managers can leverage the cross-channel synergies emanating from online trust and ease-of-use beliefs to enhance the adoption of the $\mathrm{m}$-service. The results also suggest that, to enhance wider adoption, the marketing managers of $\mathrm{m}$-services need to mitigate the status-quo-bias effects emanating from online-service facilitating conditions, and lower online-service risk perceptions.
\end{abstract}

\section{Introduction}

With the deployment of third generation (3G) mobile communication technologies, mobile commerce has seen rapid development around the world. By accessing the Internet via cell phones and other mobile terminals, users can utilise a variety of mobile (m-) services such as mobile search, mobile banking, mobile games and mobile instant messaging (Zhou, 2011). In a multichannel context, mservices can be an alternative (substitute) channel or a complementary channel to the existing online channel. Firms implementing a multichannel strategy may prefer that clients use the mobile channel as a complementary channel to the online channel rather than as a substitute, given the potential benefits for a firm offering the use of multiple channels to the same client. In a multichannel context, customers do not consider channels in isolation. Rather, customers' cognitive evaluations in relation to different channels interact with each other to affect adoption behaviour of channels (MontoyaWeiss, Voss \& Grewal, 2003; Van Birgelen, de Jong \& de Ruyter, 2006). Thus customers' perceptions of one channel influence their perceptions of another channel offered by the same firm. These cross-channel cognitive evaluations can result in evaluative dissynergies and synergies that can influence customers' adoption behaviour of alternative channels. By focusing on cross-channel cognitive evaluations, the causes and mechanisms of channel dissynergies and synergies can be explored in depth (Falk, Schepers, Hammerschmidt \& Bauer, 2007). In line with the notion of cross-channel cognitive evaluations, a crosschannel evaluative dissynergy would occur when a customer's evaluation of one channel results in an evaluative conflict with another channel of the same firm (Falk et al., 2007). On the other hand, a cross-channel evaluative synergy would occur when a customer's evaluation of one channel results in an evaluative concordance with another channel of the same firm (Falk et al., 2007).

There is a paucity of research on online-mobile cross-channel cognitive evaluations. Consumer behaviour research into mservices has so far focused primarily on three topics: (1) what drives the adoption of m-services (c.f. Gu, Lee \& Suh, 2009; Luarn \& Lin, 2005), (2) how this technology channel differs from other channels (c.f. Shankar \& Balasubramanian, 2009), and (3) post-adoption of m-services from a consumer behaviour perspective (c.f. Ha, Chung, Hamilton \& Park, 2010). The potential impact of evaluative synergies and dissynergies in cross-channel evaluations has largely been ignored. To address this gap in the body of knowledge associated with multichannel marketing and m-service adoption, the following objective was addressed in this study: To identify cross-channel cognitive evaluations influencing salient beliefs in m-service adoption.

This study offers two important contributions. Firstly, from a conceptual viewpoint, we have developed a model that is based on established multichannel theories. This model makes a conceptual contribution as it draws a holistic picture of evaluative synergies and dissynergies between the online service and the m-service in a multichannel context. From an empirical viewpoint, we make a contribution by testing the conceptual model with a large sample. The empirical part of the study provides sound evidence of the influence of crosschannel evaluations (synergies and dissynergies) emanating 
from the online service on the salient beliefs that influence mservice adoption.

The rest of the paper is organised as follows. In the next section the conceptual model that was used in the study to address the study's primary objective is developed. After the model development section, the research methodology used in the study is described, followed by the results emanating from the data analysis phase. Next the results are discussed and theoretical and managerial implications are presented. The paper concludes with the limitations of the study and suggestions for future research.

\section{Conceptual framework and formulation of hypotheses}

Based on the review of relevant literature, the conceptual model in Figure 1 was developed to address the objective of the study. As can be seen from the model in Figure 1, six cross-channel cognitive evaluations were hypothesised in the model of m-service use intention in an online service multichannel context.

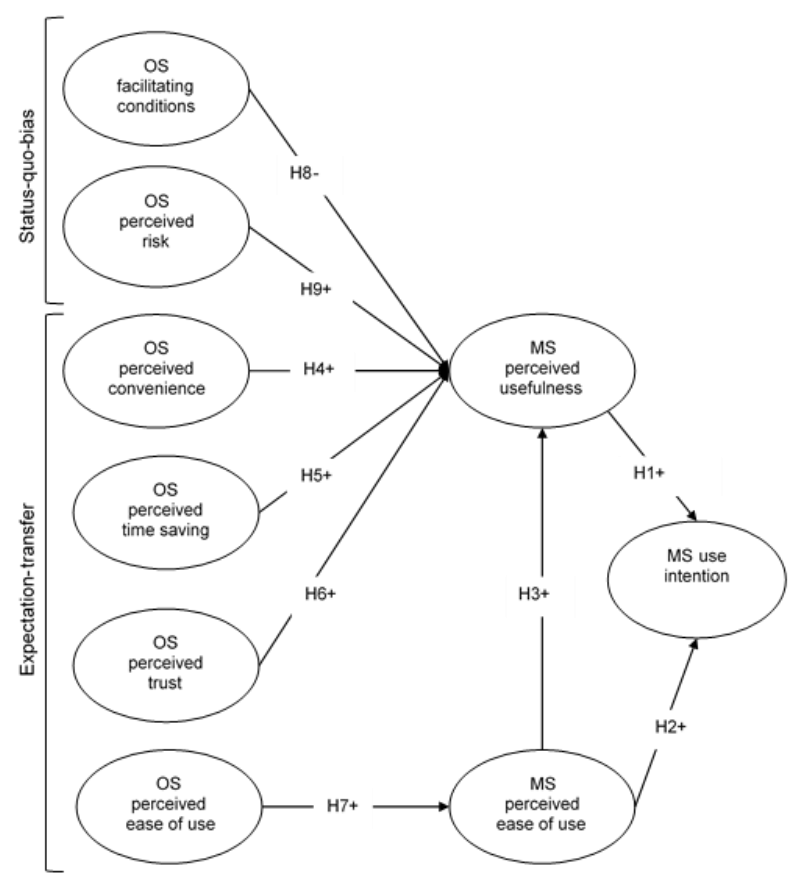

OS = Online service, MS = Mobile service

\section{Figure 1: Conceptual model}

\section{Salient beliefs in m-service adoption}

In this study the two salient beliefs influencing behavioural intention to use m-services were based on the Technology Acceptance Model (TAM). TAM is an adaptation of the Theory of Reasoned Action (TRA), which has its origins in social psychology. According to TAM two specific beliefs, perceived ease of use and perceived usefulness, determine one's behavioural intention to use a technology (Davis, 1989). Perceived usefulness is defined as the degree to which a person believes that using a particular technology will enhance his [or her] performance. Perceived ease of use refers to the extent to which a person believes that using a technology will be free of effort. Furthermore, TAM also posits that ease-of-use perceptions positively influence the usefulness perceptions of an information system (IS). According to Davis (1989), the theoretical importance of an IS's perceived usefulness and perceived ease of use as determinants of user behaviour is confirmed by several diverse lines of research. Firstly, the perceived useperformance contingency in Robey (1979) parallels the definition of perceived usefulness. Secondly, research by Bandura (1982) on self-efficacy, defined as "judgments of how well one can execute courses of action required to deal with prospective situations", confirms the importance of, and is similar to, perceived ease of use. Over the years TAM meta-analysis studies such as King and He (2006), Lee, Kozar and Larsen (2003) and Sun and Zhang (2006) confirmed the robustness of the TAM to predict IS adoption behaviour. The following hypotheses were therefore included in the study:

\section{$H^{I}$ : Perceived usefulness of the $m$-service positively influences intention to adopt the m-service}

\section{$H^{2}$ : Perceived ease of use of the $m$-service positively influences intention to adopt the m-service}

$H^{3}$ : Perceived ease of use of the m-service positively influences the perceived usefulness of the $m$-service

\section{Expectation-transfer effects between the online service and the m-service}

In a multichannel context, expectation-transfer is the theoretical base for explaining evaluative synergies between two channels (Bhatnagar, Lurie \& Zeithaml, 2003). The primary stimulus guiding expectation-transfer in a multichannel context is that the two channels must be perceived to be similar by the customer (Bhatnagar et al., 2003). Similarity plays a fundamental role in the theories of knowledge and behaviour, as it serves as an organising principle by which individuals classify objects, form concepts, and make generalisations. Similarity can be described as a function of common and distinctive features weighted for salience and importance (Tversky, 1977). As similarity is also a relation of proximity that holds between two objects, these judgments depend of the context and the frame of reference. Objects, events or entities form a category because they are similar to one another (Murphy \& Medin, 1985). An object is judged to be prototypical of a category when it has attributes that are in common with other members of the same category and are distinct from members of contrasting categories (Rosch \& Mervis, 1975). A prototypical object thus exemplifies the category to which it belongs. Prototypicality is therefore a measure of the relation of proximity between two subjects. Generalisations can be made between the objects, events or entities belonging to the same category due to the similarity between them. On the other hand, individuals' estimates of similarity may also be influenced by their knowledge that the entities being 
compared are in the same (or different) categories (Murphy \& Medin, 1985).

Taking into consideration the discussion to this point, the following scenarios illustrate how similarity judgments can guide categorisation and generalisation leading to expectation-transfer between channels in a multichannel context. A user of the online service may categorise the two services (online and mobile) as 'anytime, anywhere' selfservices, and thus conclude that both services should offer similar benefits in terms of convenience and time saving. Alternatively, a customer who is cognisant of the fact that the online service and the m-service are 'anytime, anywhere' self-services offered by a particular firm, may conclude that both services offer the benefits of convenience and time saving. Considering the potential of expectation-transfer effects between the online service and the m-service offered by a specific firm, arguments will be presented in the rest of this section that online-service benefits (specifically convenience and time saving), trust and ease-of-use perceptions positively influence salient m-service beliefs because of expectation-transfer.

For consumers the two main extrinsic motivations to use online services may be convenience and time saving. According to Yoon and Kim (2007), the concept of convenience entails dimensions such as time, place, acquisition, use and execution. They argued that in the context of using technology, the 'acquisition' dimension and the 'use' dimension are not necessarily relevant. They also reasoned that, in the use of technology to access a service, there is no acquisition; and that the 'use' dimension is more closely related to ease of use, which is a construct in the TAM. Therefore, online-service convenience exemplifies having an online service to use at a time and place that is convenient to the user. Time saving is also strongly associated with the usefulness of ubiquitous electronic services (c.f. Mallat, Rossi, Tuunainen \& Öörni, 2009; Pagani, 2004). For example, Suki, Ramayah and Suki (2008) reported that online shopping provides a time-saving benefit over traditional offline channels. Likewise, Heung (2003) emphasised that online-travel services offer a time-saving benefit for travellers. Both online and mobile services are per se ubiquitous electronic services, and both e-services offer convenience and time-saving benefits (Aldás-Manzano, Ruiz-Mafe \& Sanz-Blas, 2009). As time saving and convenience are dimensions of the perceived usefulness of an e-service (Eriksson \& Nilsson, 2007), users of the online service of a firm could draw on their convenience and timesaving perceptions to frame the perceived usefulness of the $\mathrm{m}$-service. Therefore, cross-channel evaluative synergies were hypothesised to be underpinned by the expectationtransfer between online-service convenience and time-saving beliefs on the one hand, and $\mathrm{m}$-service usefulness perceptions on the other. Against this background, the following hypotheses were addressed in this study:

$\mathrm{H}^{4}$ : Perceived convenience of the online service positively influences the usefulness perceptions of the $m$-service
$H^{5}$ : Perceived time saving of the online service positively influences the usefulness perceptions of the m-service

Trust is not only a central tenet in most business relationships and transactions, but also a key factor in the adoption of online services. Trust beliefs can be defined as the confident trustor perception that the trustee has attributes that are beneficial to the trustor (McKnight, Choudhury \& Kacmar, 2002). Although many types of trust beliefs are alluded to in the literature, three trusting belief types are more prominent: competence, benevolence and integrity (Gefen, Karahanna \& Straub, 2003; Zhang \& Zhang, 2005). In this study it was hypothesised that trust in the online service leads to enhanced perceived usefulness of the m-service offered by the same firm. This contention was based on several arguments. In general, trust beliefs are important because trust helps to reduce fraud and potential risk caused by the opportunistic behaviour of e-service providers (Gu et al., 2009). Thus it is reasonable to assert that perceived trust is a predictor of the perceived usefulness of an IS (Ha \& Stoel, 2009; Pavlou, 2003). Furthermore, trust transfer between channels of the same firm, generally referred to as inter-channel trust transfer, is an established phenomenon in multichannel marketing (Lu, Yang, Chau \& Cao, 2011). Trust transfer is a cognitive process that may arise from one familiar context and transfer to a new context (Lin, Lu, Wang \& Wei, 2011). Trust transfer entails three actors: the trustor, the trustee and a third person who is a broker in the trust-belief transfer process (Stewart, 2003). The trustor is the individual making trust judgments, the trustee is the entity whose trustworthiness is assessed by the trustor, and the third person is the broker in the trust belief transfer process. Trust transfer to the trustee would take place when there is a close relationship between the trustee and the third person, and the trustor trusts in the third person. Thus, because the online service and the m-service are 'anywhere, anytime' e-services offered by the same firm in a multichannel context, the competence, benevolence and integrity beliefs forming perceived trust in the online service of a particular firm would serve as a proxy for the perceived trust in the m-service of the same firm. The study of Lin et al. (2011) showed that trust transfer, which is a cognitive process underpinned by expectation-transfer, may arise from the online service to the m-service of a particular firm, resulting in online trust influencing m-service usefulness. Based on the discussion to this point, and drawing on the empirical evidence reported by Lin et al. (2011), it was hypothesised that a cross-channel cognitive evaluative synergy exists between perceived trust in the online service and the perceived usefulness of the $\mathrm{m}$ service of a particular firm. Therefore, the following hypothesis was addressed in this study:

\section{$H^{6}$ : Perceived trust in an online service positively influences the perceived usefulness of the $m$-service}

According to the TAM, ease-of-use beliefs are salient beliefs in the technology adoption process (Davis, 1989). The userinterface plays an important role in users' ease-of-use perceptions of an e-service (Kumar \& Venkatesan, 2005; Oded \& Chen, 2008). M-services are typically modified versions of the online service for mobile devices (Mallat, 
Rossi \& Tuunainen, 2004). In other words, m-services transited from web services have the unique feature that they possess a strong resemblance to the web service. This similarity is reflected in the functional consistency between the web service and the m-service of the same firm (Wang, Shen \& Sun, 2013). Moreover, users of the online service would expect functional similarities between the online and the m-service, as it is the same service delivered through different channels. Furthermore, in the multichannel marketing context a firm's ability to design an online service that is easy to use should be a signal to the user that the firm has the necessary resources and skills to develop an m-service that may also be easy to use. Therefore, the relationship between an online-service's perceived ease of use and an mservice's perceived ease of use was also guided by expectation-transfer resulting in cross-channel evaluative synergy. The following hypothesis was therefore considered:

$H^{7}$ : Perceived ease of use of the online service positively influences the perceived ease of use of the $m$-service

\section{Status-quo-bias and cross-channel dissynergies}

The theoretical base for cross-channel evaluative dissynergies is status-quo-bias. Status-quo-bias suggests that cross-channel dissynergies may hinder the adoption of $\mathrm{m}$ services. Status-quo-bias can be described as a preference for the current state of affairs, regardless of whether the alternative offers a higher utility (Falk et al., 2007). In information technology studies the status-quo-bias phenomenon is explained in terms of rational decisionmaking theory, cognitive misperception, and psychological commitment (cf. Kim \& Kankanhalli, 2009; Samuelson \& Zeckhauser, 1988). Rational decision-making theory predicts that when expected costs exceed expected benefits, statusquo-bias will result. Cognitive misperception relates to loss aversion, and refers to the tendency of individuals to give greater weight to potential losses than to potential gains of the same amount. In other words, "changes for the worse (losses) loom larger than equivalent changes for the better" (Kahneman, Knetsch \& Thaler, 1991). Beliefs about potential loss aversion can thus also lead to status-quo-bias, as even small losses as a result of changing from the current situation could be perceived as larger than they actually are (Kim \& Kankanhalli, 2009). Psychological commitment refers to sunk costs due to previous commitments, social norms, and the efforts by the individual to feel in control. In this study we investigated two cross-channel dissynergies based on statusquo-bias theory. We argued, firstly, that favourable onlineservice facilitating conditions lead to psychological commitment towards the online service, resulting in statusquo-bias behaviour. Secondly, we argued that decreased online-service risk perceptions can also lead to status-quobias.

The Decomposed Theory of Planned Behaviour proposes that the facilitating conditions construct (a component of perceived behavioural control) is an important one to consider in technology adoption behaviour. 'Facilitating conditions' relate to the external resource constraints of the control beliefs structure (Taylor \& Todd, 1995). Taylor and Todd (1995) pointed out that the facilitating conditions construct consists of two dimensions of control beliefs. The first dimension relates to resource factors such as time and money, while the second relates to technology compatibility issues that may constrain usage. In typical m-service adoption research (in other words, studies incorporating determinants of behavioural intention manifesting in the m-service only), it has been demonstrated that m-service facilitating conditions positively influence usefulness perceptions of the m-service (cf. Gu et al., 2009; Zhou, Lu \& Wang, 2010). However, in the current study - which focuses on crosschannel evaluations - it was hypothesised that online-service facilitating conditions exert a negative influence on the perceived usefulness of the m-service. In other words, an evaluative dissynergy was hypothesised based on status-quobias theory. According to Kim and Kankanhalli (2009), facilitating conditions as a resistance-to-change (status-quobias) factor in technology adoption can be explained by a user's psychological commitment to feel in control by not switching to an unknown system or to an unfamiliar way of working in which he/she is not fully in control. In other words, in a status-quo-bias scenario a user's exiting onlineservice facilitating conditions supports his/her needs through the use of the online service to such an extent that he/she does not see the need to adopt the m-service, which will be regarded as an unfamiliar channel. Therefore, the following cross-channel evaluative dissynergy hypothesis was addressed in this study:

\section{$H^{8}$ : Online-service facilitating conditions negatively influence the perceived usefulness of the $m$-service}

Perceived risk can be an important barrier to consumer acceptance of electronic (e-) services (Featherman \& Pavlou, 2003). If consumers perceive some risk in using an e-service, it will reduce the perceived usefulness of the service (Gefen et al., 2003; Lu, Hsu \& Hsu, 2005). Therefore, the influence of online-service risk perceptions must be considered in this study. To date, the influence of risk perceptions has not received any attention in studies exploring cross-channel cognitive evaluations. Although online services and $\mathrm{m}$ services are offered through different information communication channels (wired networks vs wireless networks) (Zhou et al., 2010), they are prone to similar risks. Online-services users, depending on the type of online service, are exposed to risks such as performance risk, social risk, time risk, privacy risk, and financial risk. For example, mobile shoppers have to reveal personal and financial information when purchasing goods (Kumar \& Mukherjee, 2013). Mobile shoppers are therefore exposed to similar risks as online shoppers, such as financial and privacy risks. Mobile-banking users are similarly exposed to performance risk, financial risk, time risk, psychological risk, and privacy risk (Luo, Li, Zhang \& Shim, 2010), as well as social risk (Li \& Bai, 2010) - just like internet-banking users. In general, mobile transactions include an element of financial, performance and security risk (Kleijnen, De Ruyter \& Wetzels, 2007) that are typically associated with online transactions. Based on the similar nature of the risks between types of online and m-services, one can conclude that because 
of entitativity, online-service risk beliefs may serve as a proxy for m-service risk beliefs; and so it can be expected that online-service risk beliefs will negatively influence the perceived usefulness of the m-service. However, onlineservice risk perceptions could rather be a source of statusquo-bias for non-users of the m-service. Users of the online service have a reasonable understanding of the risks related to the use of the service, and have adapted their usage of the online service to minimise these risks. This proposition is tenable, as Forsythe and Shi (2003) reported that risk perceptions associated with an online service decrease as experience with the service increases. On the other hand, they (the users of the online service) may be more uncertain about the risks of using the m-service (due to lack of experience) and how to mitigate these risks. Hence, this uncertainty would make the online service the rational choice, consistent with status-quo-bias theory. In other words, a cross-channel evaluative dissynergy based on status-quo-bias may arise between online-service risk beliefs and $\mathrm{m}$-service usefulness beliefs - as online-service risk perceptions decrease, $\mathrm{m}$ service usefulness perceptions also decrease. The following hypothesis was therefore addressed in this study:

$H^{9}$ : Perceived risk of the online service positively influences the perceived usefulness of the mobile service

To summarise, our model of m-service adoption by onlineservice users in a multi-channel context proposes that four potential expectation-transfer effects and two status-quo-bias effects can influence m-service usefulness and ease-of-use perceptions. In our conceptual model we did not address relationships between online-service trust and risk, onlineservice facilitating conditions and ease of use, or onlineservice facilitating conditions and time saving and convenience. The main reason for not addressing these relationships is that they are confirmed in other studies, and have become common knowledge. A second reason is that the findings related to these relationships do not add value to the understanding of cross-channel evaluations. The (potential) influences of these constructs are, however, accounted for in the estimation of the structural model by the inclusion of correlations between all exogenous variables.

Next, the empirical testing of the model is reported.

\section{Method}

\section{Target population and sampling}

To test the conceptual model, data were obtained from internet banking users who were not using the mobilebanking service offered by their bank. Thus the target population for the study was defined as bank clients aged 18 years and older who are using only internet banking. Given the constraint of bank clients' privacy rights, a sampling frame could not be obtained from any bank. Thus a nonprobability, convenience sampling method was used. Invitations to participate in the survey were posted on an online auction and travel booking site and on the Facebook alumni page of the university at which one of the researchers was employed. Additionally, email invitations were sent to all employees in a large national service firm and to the alumni of the university at which one of the researchers was employed.

\section{Data collection}

In the absence of a sampling frame, and taking into consideration the sampling criterion that all respondents must be users of internet banking, the most appropriate method to collect data was an online questionnaire. After checking all completed questionnaires for correct completion, eliminating all double submissions, and checking that the respondents banked with formal financial institutions that offer mobilebanking services, a sample of 666 non-users of mobile banking was obtained. Of the 666 respondents, 258 were male and 408 female. As could be expected, the most prominent age groups represented in the sample were 21-30 and 31-40 years of age. Together these two age groups made up 67.1 per cent of the sample. Fourteen per cent of the respondents were older than 50 years of age. All the respondents were customers of commercial banks that offer both online- and mobile-banking services. The online- and mobile-banking services of the banks provided at least the same basic functionality.

To confirm that the respondents were users of the internetbanking service, internet banking use information was collected. Based on this information, the use of internet banking for four banking transactions in a typical month was calculated. The results in Table 1 show that, of those respondents who use internet banking to pay accounts, they pay on average 74 per cent of their accounts each month using internet banking. Furthermore, those respondents who do cash transfers by means of internet banking do 93 per cent of their cash transfers online. The respondents also did most of their balance enquiries ( 89 per cent) and drawing of account statements (89 per cent) in a typical month using internet banking.

Table 1: Self-reported use of internet banking by the users of only internet banking

\begin{tabular}{c|c|c|c}
\hline $\begin{array}{c}\text { Bank } \\
\text { transactions }\end{array}$ & $\begin{array}{c}\text { Percentage of } \\
\text { respondents } \\
\text { conducting } \\
\text { banking } \\
\text { activity }\end{array}$ & $\mathbf{N}$ & $\begin{array}{c}\text { Mean percentage } \\
\text { use of internet } \\
\text { banking for } \\
\text { banking activity }\end{array}$ \\
\hline $\begin{array}{c}\text { Account } \\
\text { payments }\end{array}$ & 99 & 661 & 74 \\
\hline $\begin{array}{c}\text { Cash } \\
\text { transfers }\end{array}$ & 96 & 636 & 93 \\
\hline $\begin{array}{c}\text { Balance } \\
\text { enquiries }\end{array}$ & 96 & 639 & 89 \\
\hline $\begin{array}{c}\text { Account } \\
\text { statements }\end{array}$ & 83 & 555 & 89 \\
\hline
\end{tabular}

\section{Measurement}

Scales used in previous studies were used to collect the data, and modifications to the scales were made where necessary 
to reflect the context of the study. Respondents' beliefs about internet and mobile banking were measured using a 7-point Likert scale ( $1=$ strongly disagree; $7=$ strongly agree), except for internet-banking risk perceptions, which were measured making use of a semantic-differential scale ( $1=$ not at all risky, $7=$ very risky).

A pilot test was conducted before the questionnaire was launched online. The purpose of the pilot testing phase was to assess the measurement properties of the scales. The pilot testing phase consisted of two stages. In the first stage the validity of the items measuring the constructs was assessed, based on a face validity assessment. The face validity of the scales was assessed by a panel of two academics specialising in electronic commerce, and three bank clients. Based on the feedback from the panel, the wording of some of the items was changed. The second stage of the pilot testing phase entailed the assessment of construct reliability by means of coefficient alpha and the unidimensionality of scales by means of an exploratory factor analysis (EFA). Based on the results of the Cronbachs' Alpha test and EFA, further modifications to the scales were made. The final items used to measure each construct in the study are presented in Appendix 1.

\section{Data analysis}

To analyse the data, frequency tables and cross tabulations were used, along with co-variance-based structural equations modelling (SEM).

Before the hypotheses were tested using the computer program EQS 6.2, the psychometric properties of the measurement model were assessed by means of a confirmatory factor analysis (CFA). The validity of the measurement model was assessed by considering model fit indices, as well as the validity of the constructs forming the measurement theory. Construct validity was examined by assessing the measurement model for convergent and discriminant validity (Hair, Black, Babin \& Anderson, 2010). Convergent validity was assessed by considering factor loadings, variances extracted, and construct reliability. To meet the criteria of convergent validity, the factor loadings in the measurement model should be significant and 0.50 or higher, and ideally 0.70 or higher (Hair et al., 2010). The average variance extracted (AVE) should be 0.50 or higher. The construct reliability (CR) value of each latent variable should be 0.70 or higher to indicate adequate convergence or internal consistency (Hair et al., 2010). Discriminant validity was assessed by using the method recommended by Fornell and Larcker (1981). This method entails comparing the average variance extracted for each construct with the shared variance between constructs. The shared variance between two constructs is the squared correlation between the two constructs. For evidence of discriminant validity, the average variance extracted for both constructs must be higher than the shared variance between the two constructs.

\section{Results}

\section{Assessment of the measurement model}

The assessment of the measurement model showed acceptable fit, and it presented sufficient evidence of construct validity. The $\mathrm{S}-\mathrm{B} \chi^{2} / \mathrm{df}$ was 1.741 , the CFI and IFI were 0.971 and 0.971 respectively, and the RMSEA was 0.033 .

The standardised items loadings (SW), construct reliability (CR), and average variance extracted (AVE) values for each construct are presented in Table 2. As can be seen from Table 2 , almost all of the standardised loadings were above 0.7 , except for IBFC3, which was 0.601 . The construct reliability of all constructs was above 0.7 and the AVEs above 0.5 . Thus the results provide adequate evidence of convergent validity.

Table 2: Construct reliability and validity of the users of only internet banking measurement model

\begin{tabular}{|c|c|c|c|c|}
\hline CONSTRUCT & ITEM & S.W. & Reliability & AVE \\
\hline \multirow{5}{*}{$\begin{array}{l}\text { IB convenience } \\
\quad(\text { IBCON) }\end{array}$} & IBCON1 & 0.899 & \multirow{5}{*}{0.940} & \multirow{5}{*}{0.759} \\
\hline & IBCON2 & 0.956 & & \\
\hline & IBCON3 & 0.919 & & \\
\hline & IBCON4 & 0.844 & & \\
\hline & IBCON5 & 0.718 & & \\
\hline \multirow{5}{*}{$\begin{array}{l}\text { IB time saving } \\
\text { (IBTS) }\end{array}$} & IBTS1 & 0.727 & \multirow{5}{*}{0.901} & \multirow{5}{*}{0.646} \\
\hline & IBTS2 & 0.745 & & \\
\hline & IBTS3 & 0.841 & & \\
\hline & IBTS4 & 0.826 & & \\
\hline & IBTS5 & 0.869 & & \\
\hline \multirow{3}{*}{$\begin{array}{c}\text { IB facilitating } \\
\text { conditions (IBFC) }\end{array}$} & IBFC1 & 0.780 & \multirow{3}{*}{0.782} & \multirow{3}{*}{0.549} \\
\hline & IBFC2 & 0.823 & & \\
\hline & IBFC3 & 0.601 & & \\
\hline \multirow{4}{*}{ IB trust (IBT) } & IBT1 & 0.752 & \multirow{4}{*}{0.894} & \multirow{4}{*}{0.679} \\
\hline & IBT2 & 0.825 & & \\
\hline & IBT3 & 0.835 & & \\
\hline & IBT4 & 0.880 & & \\
\hline \multirow{4}{*}{ IB risk (IBR) } & IBR1 & 0.922 & \multirow{4}{*}{0.957} & \multirow{4}{*}{0.848} \\
\hline & IBR2 & 0.926 & & \\
\hline & IBR3 & 0.908 & & \\
\hline & IBR4 & 0.928 & & \\
\hline \multirow{4}{*}{$\begin{array}{l}\text { IB ease of use } \\
\quad \text { (IBEOU) }\end{array}$} & IBEOU1 & 0.808 & \multirow{4}{*}{0.899} & \multirow{4}{*}{0.691} \\
\hline & IBEOU2 & 0.709 & & \\
\hline & IBEOU3 & 0.912 & & \\
\hline & IBEOU4 & 0.882 & & \\
\hline \multirow{4}{*}{$\begin{array}{l}\text { MB usefulness } \\
\text { (MBU) }\end{array}$} & MBU1 & 0.938 & \multirow{4}{*}{0.970} & \multirow{4}{*}{0.889} \\
\hline & MBU2 & 0.902 & & \\
\hline & MBU3 & 0.970 & & \\
\hline & MBU4 & 0.961 & & \\
\hline \multirow{3}{*}{$\begin{array}{l}\text { MB ease of use } \\
\text { (MBEOU) }\end{array}$} & MBEOU1 & 0.718 & \multirow{3}{*}{0.897} & \multirow{3}{*}{0.746} \\
\hline & MBEOU2 & 0.944 & & \\
\hline & MBEOU3 & 0.911 & & \\
\hline \multirow{4}{*}{$\begin{array}{l}\text { MB intention } \\
\text { (MBI) }\end{array}$} & MBI1 & 0.850 & \multirow{4}{*}{0.931} & \multirow{4}{*}{0.770} \\
\hline & MBI2 & 0.919 & & \\
\hline & MBI3 & 0.854 & & \\
\hline & MBI4 & 0.886 & & \\
\hline
\end{tabular}

An inspection of the squared correlation between each pair of constructs in the measurement model and the AVE for each associated construct showed that the AVE for each construct 
was greater than the squared correlation (see Table 3). The results in Table 3 therefore provide adequate evidence of discriminant validity according to the approach proposed by Fornell and Larcker (1981).

Table 3: Average variance extracted compared with squared correlations

\begin{tabular}{l|r|r|r|r|r|r|r|r|r}
\hline & MBU & \multicolumn{1}{|c|}{ MBEOU } & \multicolumn{1}{c|}{ MBI } & IBEOU & IBT & IBCON & IBTS & IBFC & IBR \\
\hline MBU & $\mathbf{0 . 8 8 9}$ & & & & & & & & \\
\hline MBEOU & 0.190 & $\mathbf{0 . 7 4 6}$ & & & & & & & \\
\hline MBI & 0.432 & 0.123 & $\mathbf{0 . 7 7 0}$ & & & & & & \\
\hline IBEOU & 0.006 & 0.045 & 0.010 & $\mathbf{0 . 6 9 1}$ & & & & & \\
\hline IBT & 0.013 & 0.023 & 0.002 & 0.193 & $\mathbf{0 . 6 7 9}$ & & & & \\
\hline IBCON & 0.007 & 0.038 & 0.000 & 0.183 & 0.101 & $\mathbf{0 . 7 5 9}$ & & & \\
\hline IBTS & 0.002 & 0.040 & 0.000 & 0.184 & 0.120 & 0.581 & $\mathbf{0 . 6 4 6}$ & & \\
\hline IBFC & 0.000 & 0.030 & 0.001 & 0.203 & 0.151 & 0.340 & 0.376 & $\mathbf{0 . 5 4 9}$ & \\
\hline IBR & 0.003 & 0.000 & 0.002 & 0.058 & 0.217 & 0.013 & 0.010 & 0.047 & $\mathbf{0 . 8 4 8}$ \\
\hline
\end{tabular}

Collectively the results of the assessment of the measurement model for convergent and discriminant validity presented satisfactory evidence of construct validity.

\section{Common method bias and collinearity}

Common method variance could bias the findings when both independent and dependent measures are obtained from the same source, as in the case in this study. We assessed method bias using Harman's single-factor test (Podsakoff, MacKenzie, Lee \& Podsakoff, 2003). The basic assumption of Harman's single-factor test is that if a substantial amount of common method variance is present, either (a) a single factor will emerge from the factor analysis, or (b) one general factor will account for the majority of the covariance among the measures. From the exploratory factor analysis nine factors emerged. Furthermore, the factor that accounted for the most variance accounted for only 26.8 per cent of the variance among the measures. Thus common method variance does not appear to be a problem in this study.

Collinearity is present when there is an approximate linear relationship between some of the predictor variables in the study. High levels of collinearity have several potentially undesirable consequences, such as parameter estimates that fluctuate dramatically with negligible changes in the sample, parameter estimates with sign changes that are 'wrong' in terms of theoretical considerations, theoretically 'important' variables with insignificant coefficients, and the inability to determine the relative importance of collinear variables (Mason \& Perreault Jr, 1991). To assess whether collinearity was a threat to the results, the variance inflation factor (VIF) and the tolerance value for each independent variable were calculated. The highest VIF was 2.304 and the lowest tolerance value was 0.434 . These results suggest collinearity was not a threat to the results.

\section{Assessment of the structural model}

EQS 6.2 was used to create the co-variance-based structural equations model. The values of the model fit indices were $\mathrm{S}-\mathrm{B} \chi^{2} / \mathrm{df}=1.744, \quad \mathrm{CFI}=0.0 .971, \quad \mathrm{ILI}=0.971, \quad$ and $\mathrm{RMSEA}=0.033$. Considering the recommended cut-off values proposed in Hair et al. (2010), the conclusion was that the data adequately fitted the proposed structural model.

The structural model results in Figure 2 show that four of the six hypothesised cross-channel evaluations were supported by the data. Firstly, the results of the study confirm that mservice usefulness and ease-of-use perceptions are salient beliefs in the adoption of the m-service, and that ease-of-use perceptions influence usefulness perceptions. The influence of $\mathrm{m}$-service usefulness perceptions on use intentions was 0.622 and that of $\mathrm{m}$-service ease-of-use perceptions 0.350 $(0.080+0.434 * 0.622)$. Thus H1, H2 and H3 were accepted.

Of the four cross-channel evaluative synergies guided by expectation-transfer, two of the four relationships were significant. The results showed that online-service convenience perceptions do not influence m-service usefulness perceptions $(0.081, \mathrm{t}=1.275)$. H4 was therefore rejected. H5 was also rejected. The data did not support the hypothesis that time-saving perceptions of the online service influence usefulness perceptions of the m-service $(-0.73, t=-$ 1.048). The results of the analysis did support H6, that onlineservice trust perceptions influence m-service usefulness perceptions $(0.126, t=2.281)$. And lastly, in line with $H 7$, the results showed a positive and significant influence between online-service ease-of-use perceptions and m-service ease-ofuse perceptions $(0.219, \mathrm{t}=5.018)$.

Both hypothesised status-quo-bias effects were supported by the data. The negative influence of online-service facilitating conditions on m-service usefulness perceptions (H8) was -0.102 and significant. Likewise, the path coefficient for the influence of online-service risk perceptions on m-service usefulness perceptions (H9) was 0.092 and significant. Therefore, a decrease in online-service risk perceptions can lead to a status-quo-bias effect, as it decreases the perceived usefulness of the m-service. A summary of the results is presented in Table 4. 


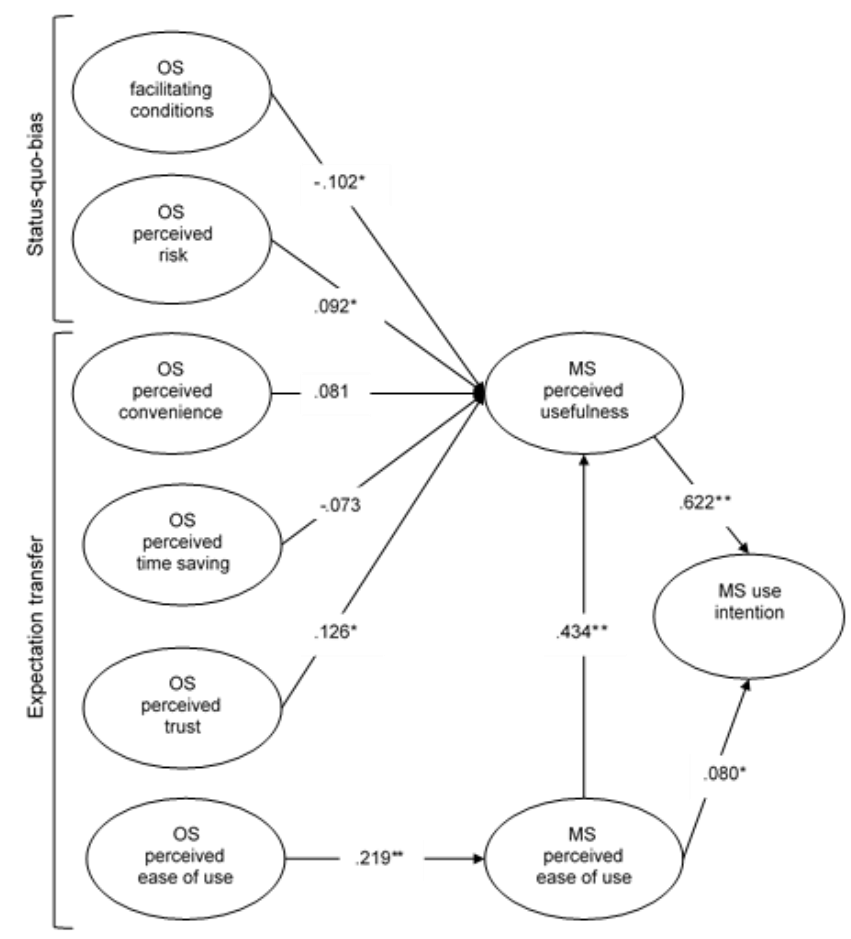

OS $=$ Online service, MS $=$ Mobile service, ${ }^{*} \rho<0.05,{ }^{* *} \rho<0.001$

Figure 2: Results of the structural model assessment

Table 4: Summary of the results

\begin{tabular}{|c|c|c|c|c|}
\hline \multicolumn{2}{|c|}{ Hypotheses } & \multicolumn{2}{|c|}{ Standardised coefficients and $t$-values } & \multirow{2}{*}{$\begin{array}{c}\text { Hypothesis } \\
\text { accepted/rejected } \\
\text { Accepted }\end{array}$} \\
\hline $\mathrm{H}^{1}$ & MS perceived usefulness -> MS use intention & 0.622 & $(17.141)$ & \\
\hline $\mathrm{H}^{2}$ & MS perceived ease of use $->$ MS use intention & 0.080 & $(2.333)$ & Accepted \\
\hline $\mathrm{H}^{3}$ & MS perceived ease of use $->$ MS perceived usefulness & 0.434 & $(10.283)$ & Accepted \\
\hline $\mathrm{H}^{4}$ & OS perceived convenience $->$ MS perceived usefulness & 0.081 & $(1.275)$ & Rejected \\
\hline $\mathrm{H}^{5}$ & OS perceived time saving $->$ MS perceived usefulness & -0.073 & $(-1.048)$ & Rejected \\
\hline $\mathrm{H}^{6}$ & OS perceived trust -> MS perceived usefulness & 0.126 & $(2.281)$ & Accepted \\
\hline $\mathrm{H}^{8}$ & OS facilitating conditions $->$ MS perceived usefulness & -0.102 & $(-1.663)$ & Accepted \\
\hline \multirow[t]{5}{*}{$\mathrm{H}^{9}$} & OS perceived risk -> MS perceived usefulness & 0.092 & $(2.151)$ & Accepted \\
\hline & $\mathrm{R}^{2}$ & & & \\
\hline & MS perceived usefulness & 0.206 & $21 \%$ & \\
\hline & MS perceived ease of use & 0.048 & $5 \%$ & \\
\hline & MS intention & 0.435 & $44 \%$ & \\
\hline
\end{tabular}

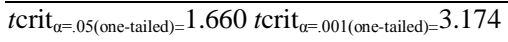

\section{Discussion}

The results of the study provided empirical evidence that online-mobile cross-channel evaluations can influence the perceived usefulness and ease of use of the m-service. Furthermore, the results of the study confirmed the role that expectation-transfer plays as the theoretical basis for understanding cross-channel evaluative synergies, and for status-quo-bias as the theoretical base for understanding cross-channel evaluative dissynergies.

Consistent with findings in earlier studies, the results indicated that inter-channel trust transfer impacts on the decision-making of users of the online service. This result implies that trust in the online service could be an important factor in assessing the usefulness of the m-service. Secondly, in terms of the adoption of m-services in a multichannel context, ease-of-use perceptions of the online service serve as a proxy for m-service ease-of-use perceptions. This finding further indicates that users of the online service anticipate similarities in the user interface between the online service and the m-service.

The statistically non-significant influences of online service convenience and time-saving perceptions on the perceived usefulness of the m-service were unexpected. The unexpectedness is because both services are ubiquitous services and offer 'anywhere, anytime' convenience and 
time-saving benefits. A possible reason for these results could be that the respondents perceived m-services as providing enhanced (unparalleled) convenience and time saving, and thus the two services are not comparable on these two characteristics.

The relevance of uncertainty costs and the presence of psychological commitment in creating status-quo-bias behaviour among users of the online service was confirmed by the two cross-channel evaluative dissynergies hypothesised in this study. The empirical results in respect of $\mathrm{H} 8$ and $\mathrm{H} 9$ indicated that favourable online-service facilitating conditions and risk perceptions reduce the perceived usefulness of the m-service offered by the same firm. As usefulness of the m-service has a significant effect on the adoption intentions, it would be important for managers of m-services to develop marketing campaigns to eliminate or strongly mitigate these status-quo-bias effects.

\section{Theoretical and managerial implications}

The theoretical contribution of the study is fourfold. Firstly, the study contributes to what is currently a very limited body of knowledge on cross-channel cognitive evaluative synergies in a multichannel marketing context by validating expectation-transfer and status-quo-bias as mechanisms underlying cross-channel synergies and dissynergies between the online service and the mobile service. Secondly, the study identifies an ease-of-use expectation-transfer effect between the online service and the m-service. Thirdly, the study identified specifically that online-service facilitating conditions and risk perceptions could contribute to statusquo-bias. And lastly, the study provides new directions for expanding the TAM, TAM2 and other theoretical models in future studies focusing on the adoption of $\mathrm{m}$-services transited from online services. Based on the results of the study, future studies can add online-service trust and risk beliefs and online-service facilitating conditions as additional determinants of the usefulness of the m-service. Onlineservice ease-of-use beliefs can also be added as a determinant of m-service ease of use. By including these cross-channel evaluations in addition to beliefs related to the m-service, the validity of the model, would be enhanced, as the expanded model would represent the real-world scenario that the adoption of the m-service takes place in a multichannel environment.

Based on the results of the study, the following recommendations can be suggested to enhance the adoption of m-services by online-service users. Firstly, to facilitate and strengthen the cross-channel synergy between online-service ease of use and m-service ease of use, perceived interface similarity must be established between the two e-services. To achieve this perceived interface similarity, the design of a firm's m-service should strongly resemble the look-and-feel and the transaction processes of the online service. This similarity-in-design consideration of the m-service would offer the required basis for the cross-channel synergy between online-service ease of use and m-service ease of use. Once interface similarities are established, the online-service users must be made aware of the similarities by means of effective marketing. For example, online guides, pamphlets, and advertisements should emphasise the similarity-in-use between the online service and the $\mathrm{m}$-service. These materials could include side-by-side screenshots of the online service and the m-service to reinforce the notion of similarity in ease of use. It is also recommended that firms offer interactive demonstrations of m-service(s) and incentivise clients to try them out. Interactive demonstrations of m-services would offer clients the opportunity to explore the m-service offered by the firm. The direct experience that online clients would obtain by using the interactive demonstrations could be valuable in developing the expectation-transfer effect between the online service and the m-service.

The status-quo-bias effects created by online-service facilitating conditions and lower risk perceptions may lead to online-service users not viewing the m-service as complementary. To overcome these status-quo barriers, firms need to communicate to online users that, although they may have regular access to the internet, the m-service is particularly useful for those situations where access to an eservice is needed in the absence of convenient access to the internet via a computer. Typical situations that illustrate the usefulness of the m-services could include instances while they (users of the online service) are on vacation, travelling, shopping in retail stores, or engaged in outdoor leisure activities. To contend with the status-quo-bias effect as the result of a decrease in online service risk perceptions, firms may rather establish an expectation-transfer effect between online-service risk perceptions and m-service usefulness perceptions. The expectation-transfer effect can be achieved by incorporating the same type of authentications that are used in the online service into the m-service of the firm, and informing online users about the similarity.

Based on the inter-channel trust transfer result, the following recommendations can also be offered to enhance usefulness perceptions of the m-service. It is recommended, firstly, that online services maintain particularly high levels of trustworthiness and ensure that clients are not exposed to any risk. To enhance trustworthiness perceptions, online services must be reliable. It is recommended, therefore, that online services are well-maintained so that any system down-time is limited, and that online services function as expected even during high-volume user times, such as the beginning or the end of a month. By building high levels of trust in online services, the cross-channel generalisation (inter-channel trust transfer) by online-service users would result in higher usefulness perceptions of the $\mathrm{m}$-service.

\section{Limitations of the study, and future research}

A limitation of the study is that the influence of offline services on salient m-service beliefs was not considered. Offline services could also influence usefulness and ease-ofuse perceptions of the m-service. A recommendation for future research, therefore, is also to consider clients' offlineservice beliefs as determinants of m-service salient adoption beliefs. 
In this study, the influence of the online service on the perceived usefulness and perceived ease of use of the mservice was investigated. A second suggestion for future research is to make use of a logistic-regression analysis to determine which beliefs about the online service and other relevant covariates increase the probability that a user of the online service would also adopt the m-service.

Thirdly, future research can extend the conceptual model in this study by including online-service satisfaction as an additional construct in the model. Online-service satisfaction can also be included as a determinant of the perceived usefulness of the m-service. Empirical testing of the relationship between online-service satisfaction and $\mathrm{m}$ service usefulness can confirm whether the relationship is an expectation-transfer effect or a status-quo-bias effect.

\section{Conclusion}

In conclusion, the purpose of the study was to investigate how online-service users' cross-channel cognitive evaluations influence salient beliefs impacting their intention to use the $\mathrm{m}$-service offered by the same firm. The study quantified the influence of cross-channel evaluations from the online service on $\mathrm{m}$-service usefulness and ease-of-use perceptions. The findings of the study could contribute to the wider application of $\mathrm{m}$-services in the future, as it provides marketing managers with unique insights into enhancing the adoption of m-services by the users of the online service.

\section{References}

Aldás-Manzano, J., Ruiz-Mafe, C. \& Sanz-Blas, S. 2009. 'Exploring individual personality factors as drivers of $\mathrm{m}$-shopping acceptance', Industrial Management \& Data Systems, 109(6): 739-757.

Bandura, A. 1982. 'Self-efficacy mechanism in human agency', American Psychologist, 37(2): 122-147.

Bhatnagar, N., Lurie, N. \& Zeithaml, V.A. 2003. 'Reasoning about online and offline service experiences: The role of domain specificty in the formation of service expectations', Advances in Consumer Research, 30: 83-384.

Davis, F.D. 1989. 'Perceived usefulness, perceived ease of use, and user acceptance of information technology', MIS Quarterly, 13(3): 319-340.

Eriksson, K. \& Nilsson, D. 2007. 'Determinants of the continued use of self-service technology: The case of internet banking', Technovation, 27(4): 159-167.

Falk, T., Schepers, J., Hammerschmidt, M. \& Bauer, H. 2007. 'Identifying cross-channel dissynergies for multichannel service providers', Journal of Services Research, 10(2): 143-160.

Featherman, M.S. \& Pavlou, P.A. 2003. 'Predicting e-services adoption: A perceived risk facets perspective', International Journal of Human-Computer Studies, 59(4): 451-474.

Fornell, C. \& Larcker, D.F. 1981. 'Evaluating structural equation models with unobservable variables and measurement error', Journal of Marketing Research, 18(1): 39-50.
Forsythe, S.M. \& Shi, B. 2003. 'Consumer patronage and risk perceptions in Internet shopping', Journal of Business Research, 56(11): $867-875$.

Gefen, D., Karahanna, E. \& Straub, D.W. 2003. 'Inexperience and experience with online stores: The importance of TAM and trust', IEEE Transactions on Engineering Management, 50(3): 307-321.

Gu, J.-C., Lee, S.-C. \& Suh, Y.-H. 2009. 'Determinants of behavioral intention to mobile banking', Expert Systems with Applications, 36(9): 11605-11616.

Ha, S., Chung, T.-L., Hamilton, J. \& Park, J. 2010. 'Moving beyond acceptance: Exploring determinants of consumer use of mobile services', International Journal of Mobile Marketing, 5(2): 30-42.

Ha, S. \& Stoel, L. 2009. 'Consumer e-shopping acceptance: Antecedents in a Technology Acceptance Model', Journal of Business Research, 62(5): 565-571.

Hair, J.F., Black, W.C., Babin, B.J. \& Anderson, R.E. 2010. Multivariate data analysis: A global perspective. New Jersey: Pearson Prentice Hall.

Heung, V.C. 2003. 'Internet usage by international travellers: Reasons and barriers', International Journal of Contemporary Hospitality Management, 15(7): 370-378.

Kahneman, D., Knetsch, J.L. \& Thaler, R.H. 1991. 'Anomalies: The endowment effect, loss aversion, and status quo bias', The Journal of Economic Perspectives, 5(1): 193-206.

Kim, H.-W. \& Kankanhalli, A. 2009. 'Investigating user resistance to information systems implementation: A status quo bias perspective', MIS Quarterly, 33(3): 567-582.

Kim, K.K., Prabhakar, B. \& Park, S.K. 2009. 'Trust, perceived risk, and trusting behavior in internet banking', Asia Pacific Journal of Information Systems, 19(3): 1-23.

King, W.R. \& He, J. 2006. 'A meta-analysis of the Technology Acceptance Model', Information \& Management, 43(6): 740-755.

Kleijnen, M., De Ruyter, K. \& Wetzels, M. 2007. 'An assessment of value creation in mobile service delivery and the moderating role of time consciousness', Journal of retailing, 83(1): 33-46.

Kumar, A. \& Mukherjee, A. 2013. 'Shop while you talk: Determinants of purchase intentions through a mobile device', International Journal of Mobile Marketing, 8(1): 23-37.

Kumar, V. \& Venkatesan, R. 2005. 'Who are the multichannel shoppers and how do they perform? Correlates of multichannel shopping behavior', Journal of Interactive Marketing, 19(2): 44-62.

Lee, K.C. \& Chung, N. 2009. 'Understanding factors affecting trust in and satisfaction with mobile banking in Korea: A modified DeLone and McLean's model perspective', Interacting with Computers, 21(5-6): 385-392.

Lee, M.-C. 2009. 'Factors influencing the adoption of internet banking: An integration of TAM and TPB with perceived risk and perceived benefit', Electronic Commerce Research and Applications, 8(3): 130-141. 
Lee, Y., Kozar, K.A. \& Larsen, K.R.T. 2003. 'The Technology Acceptance Model: Past, present, and future', Communications of AIS, 2003(12): 752-780.

Li, Z. \& Bai, X. 'Influences of perceived risk and system usability on the adoption of mobile banking service'. International Symposium on Computer Science and Computational Technology (ISCSCT), 2010. 51-54.

Liao, Z. \& Cheung, M.T. 2002. 'Internet-based e-banking and consumer attitudes: An empirical study', Information \& Management, 39(4): 283-295.

Lin, J., Lu, Y., Wang, B. \& Wei, K.K. 2011. 'The role of interchannel trust transfer in establishing mobile commerce trust', Electronic Commerce Research and Applications, 10(6): 615-625.

Lu, H.-P., Hsu, C.-L. \& Hsu, H.-Y. 2005. 'An empirical study of the effect of perceived risk upon the intention to use online applications', Information Management \& Computer Security, 13(2): 106-120.

Lu, Y., Yang, S., Chau, P.Y.K. \& Cao, Y. 2011. 'Dynamics between the trust transfer process and intention to use mobile payment services: A cross-environment perspective', Information and Management, 48(8): 393-403.

Luarn, P. \& Lin, H.-H. 2005. 'Toward an understanding of the behavioral intention to use mobile banking', Computers in Human Behavior, 21(6): 873-891.

Luo, X., Li, H., Zhang, J. \& Shim, J.P. 2010. 'Examining multidimensional trust and multi-faceted risk in initial acceptance of emerging technologies: An empirical study of mobile banking services', Decision Support Systems, 49(2): 222-234.

Mallat, N., Rossi, M. \& Tuunainen, V.K. 2004. 'Mobile banking services', Communications of the ACM, 47(5): 42-46.

Mallat, N., Rossi, M., Tuunainen, V.K. \& Öörni, A. 2009. 'The impact of use context on mobile services acceptance: The case of mobile ticketing', Information and Management, 46(3): 190-195.

Mason, C.H. \& Perreault Jr, W.D. 1991. 'Collinearity, power, and interpretation of multiple regression analysis', Journal of Marketing Research, 268-280.

Mcknight, D.H., Choudhury, V. \& Kacmar, C. 2002. 'Developing and validating trust measures for e-commerce: An integrative typology', Information Systems Research, 13(3): 334-359.

Montoya-Weiss, M.M., Voss, G.B. \& Grewal, D. 2003. 'Determinants of online channel use and overall satisfaction with a relational, multichannel service provider', Journal of the Academy of Marketing Science, 31(4): 448-458.

Murphy, G.L. \& Medin, D.L. 1985. 'The role of theories in conceptual coherence', Psychological Review, 92(3): 289-316.

Oded, N. \& Chen, Y. 2008. 'Users' personality and perceived ease of use of digital libraries: The case for resistance to change', Journal of the American Society for Information Science and Technology, 59(5): $845-851$

Pagani, M. 2004. 'Determinants of adoption of third generation mobile multimedia services', Journal of Interactive Marketing, 18(3): 46-59.
Pavlou, P.A. 2003. 'Consumer acceptance of electronic commerce: Integrating trust and risk with the Technology Acceptance Model', International Journal of Electronic Commerce, 7(3): 101-134.

Podsakoff, P.M., Mackenzie, S.B., Lee, J.-Y. \& Podsakoff, N.P. 2003. 'Common method biases in behavioral research: A critical review of the literature and recommended remedies', Journal of Applied Psychology, 88(5): 879-903.

Robey, D. 1979. 'User attitudes and management information system use', Academy of Management Journal, 22(3): 527-538.

Rosch, E. \& Mervis, C.B. 1975. 'Family resemblances: Studies in the internal structure of categories', Cognitive Psychology, 7(4): 573-605.

Samuelson, W. \& Zeckhauser, R. 1988. 'Status quo bias in decision making', Journal of Risk and Uncertainty, 1(1): 7-59.

Shankar, V. \& Balasubramanian, S. 2009. 'Mobile marketing: A synthesis and prognosis', Journal of Interactive Marketing, 23(2): 118-129.

Shih, Y.-Y. \& Fang, K. 2004. 'The use of a Decomposed Theory of Planned Behavior to study internet banking in Taiwan', Internet Research, 14(3): 213-223.

Stewart, K.J. 2003. 'Trust transfer on the world wide web', Organization Science, 14(1): 5-17.

Suki, N.M., Ramayah, T. \& Suki, N.M. 2008. 'Internet shopping acceptance: Examining the influence of intrinsic versus extrinsic motivations', Direct Marketing: An International Journal, 2(2): $97-$ 110.

Sun, H. \& Zhang, P. 2006. 'The role of moderating factors in user technology acceptance', International Journal of Human-Computer Studies, 64(2): 53-78.

Taylor, S. \& Todd, P.A. 1995. 'Understanding information technology usage: A test of competing models', Information Systems Research, 6(2): 144-176.

Torkzadeh, G. \& Van Dyke, T.P. 2002. 'Effects of training on internet self-efficacy and computer attitudes', Computers in Human Behavior, 18(5): 479-494.

Tversky, A. 1977. 'Features of similarity', Psychological Review, 84(4): 327-352.

Van Birgelen, M., De Jong, A. \& De Ruyter, K. 2006. 'Multichannel service retailing: The effects of channel performance satisfaction on behavioral intentions', Journal of Retailing, 82(4): 367-377.

Venkatesh, V., Morris, M.G., Davis, G.B. \& Davis, F.D. 2003. 'User acceptance of information technology: Toward a unified view', MIS Quarterly, 27(3): 425-478.

Wang, N., Shen, X.-L. \& Sun, Y. 2013. 'Transition of electronic word-of-mouth services from web to mobile context: A trust transfer perspective', Decision Support Systems, 54(3): 1394-1403.

Yoon, C. \& Kim, S. 2007. 'Convenience and TAM in a ubiquitous computing environment: The case of wireless LAN', Electronic Commerce Research and Applications, 6(1): 102-112. 
Zhang, X. \& Zhang, Q. 2005. Online trust forming mechanism: Approaches of an integrated model. ICEC'05, 15-17 August 2005, Xi'an, China.

Zhou, T. 2011. 'An empirical examination of users' post-adoption behaviour of mobile services', Behaviour \& Information Technology, 30(2): 241-250.

Zhou, T., Lu, Y. \& Wang, B. 2010. 'Integrating TTF and UTAUT to explain mobile banking user adoption', Computers in Human Behavior, 26(4): 760-767.

\section{Appendix 1: Scales}

Perceived usefulness of mobile banking ( $\mathrm{Gu}$ et al., 2009; Lee, 2009)

MBU1 Using mobile banking would enable me to do my banking transactions quicker

MBU2 Using mobile banking would make it easier to do my banking transactions

MBU3 Mobile banking would be useful

MBU4 Using mobile banking would enhance the efficiency of my banking activities

Perceived ease of use of mobile banking ( $\mathrm{Gu}$ et al., 2009; Luarn \& Lin, 2005)

MBEOU1 Mobile banking would be easy to use

MBEOU2 Learning to use mobile banking would be easy

MBEOU3 It would be easy to become skilful in using mobile banking

Intention to use mobile banking (Gu et al., 2009; Lee, 2009; Luarn \& Lin, 2005)

MBI1 I intend to use mobile banking regularly in the future

MBI2 Assuming that I have access to mobile banking services, I intend to use it

MBI3 I will frequently use mobile banking in the future

MBI4 I will use mobile banking for my banking needs

Perceived ease of use of internet banking (Davis, 1989; Lee, 2009)

IBEOU1 Learning to use internet banking is easy

IBEOU2 Using internet banking does not require a lot of mental effort

IBEOU3 It is easy to use internet banking to do banking transactions IBEOU4 It is easy to become skilful at using internet banking

Perceived trust in internet banking (Gu et al., 2009; Lee \& Chung, 2009)

IBT1 Internet banking is trustworthy

IBT2 Internet banking keeps its promises and commitments

IBT3 Internet banking serves the present and future interests of users

IBT4 Overall, I trust internet banking
Perceived convenience of internet banking (Liao \& Cheung, 2002; Torkzadeh \& Van Dyke, 2002)

IBCON1 Internet banking is convenient, because I can do banking activities from a place (like home or office) convenient for me

IBCON2 Internet banking is convenient, because I can do banking activities any day of the week

IBCON3 Internet banking is convenient, because I can do banking activities any time of the day

IBCON4 Internet banking is convenient, because it minimises the effort in doing banking transactions

IBCON5 Overall, internet banking is more convenient than other available modes of self-service banking

Perceived time saving of internet banking (Torkzadeh \& Van Dyke, 2002 and theory)

IBTS1 Internet banking minimises the time I spend doing banking transactions

IBTS2 Internet banking minimises my queuing time in the bank or to pay accounts at retailers

IBTS3 Internet banking saves me time since I do not always have to go to the bank to do banking transactions

IBTS4 Internet banking minimises the time pressure when doing banking transactions

IBTS5 Overall, internet banking saves me time

Internet banking facilitating conditions (Shih \& Fang, 2004; Venkatesh, Morris, Davis \& Davis, 2003)

IBFC1 Throughout every day of the week I have access to a computer that I can use for internet banking

IBFC2 I have the time to use internet banking

IBFC3 I have the money to use internet banking

Perceived risk of internet banking (Featherman \& Pavlou, 2003; Kim, Prabhakar \& Park, 2009)

IBR1 Considering the possibility of monetary loss associated with internet banking, how risky do you consider internet banking to be?

IBR2 Considering the possibility of harm to you resulting from the misuse of important personal and financial information due to the use of internet banking, how risky do you consider internet banking to be?

IBR3 Considering the possible loss of privacy because of information collected about you as you use internet banking, how risky do you consider internet banking to be?

IBR4 How risky do you rate internet banking? 